\section{A CASE OF PRIMARY CARCINOMA OF THE FALLOPIAN TUBE \\ BY}

\author{
DEREK JEFFERISS, F.R.C.O.G. \\ Consultant Gynaecologist, Exeter Clinical Area
}

The incidence of primary carcinoma of the Fallopian tube is given by various authors as $0.2-0.4 \%$ of all cases of pelvic cancer, and so far fewer than 600 have been reported in the literature. Rhu (1957) records 525 in addition to two of his own. The literature has also been reviewed and cases reported by Bancroft-Livingston (1946), Hu, Taymor, and Hertig (1950), and others. The rarity of the condition prompted the publication of this single case, with photographs of the specimen.

\section{Case Report}

A widow aged 72 had noticed a lump in the lower abdomen for several weeks. She consulted her general practitioner on account of vaginal bleeding of moderate amount. Examination revealed a tumour just palpable

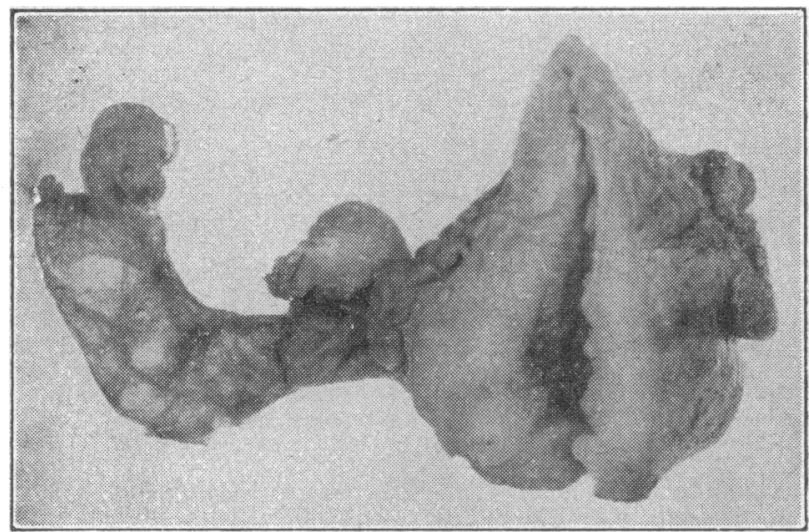

Fig. 1.-Uterus with left tube opened to show the dilatation caused by the bleeding, with the tumour at the fimbrial end.

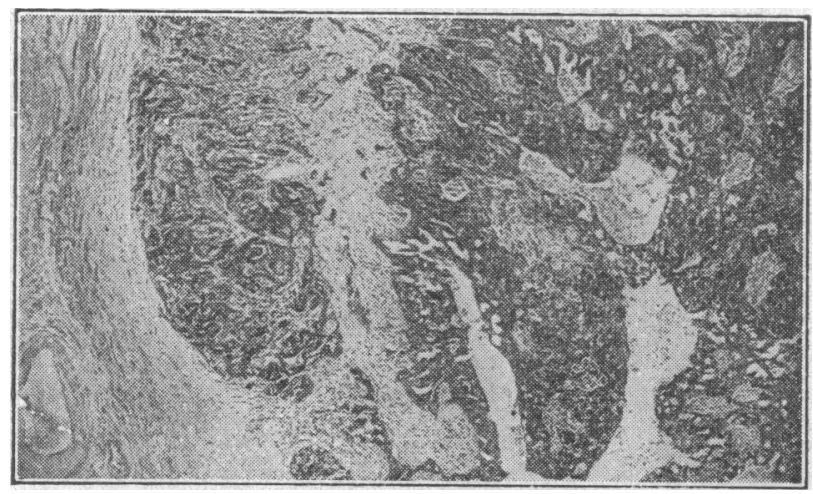

FIG. 2.-Microscopical appearance of carcinoma of the Fallopian tube. $(\times 22.5)$

above the symphysis pubis, but vaginal examination was negative. After this examination there was fairly severe vaginal bleeding accompanied by a watery discharge and disappearance of the "lump."

Three days later I saw the patient. Abdominal examination was negative except for a low mid-line scar. Vaginal examination revealed a small uterus with, on speculum inspection, an apparently healthy cervix. There was no bleeding or discharge.

There was a past history of "failed forceps" followed by caesarean section and no further pregnancies. Periods had stopped 12 years previously, at the age of 60 , and there had been no bleeding or discharge until the present occurrence. A diagnosis of carcinoma of the body of the uterus was made.

Operation.-The abdomen was opened by a low transverse incision. The uterus, ovaries, and right Fallopian tube appeared normal. The left tube was dark purple in colour and was distended in its outer two-thirds to a diameter of $\frac{3}{4}$ in $(2 \mathrm{~cm}$.). The proximal one-third was not distended. Hysterectomy and bilateral salpingo-oophorectomy was performed. Owing to technical difficulties the uterus was. removed supravaginally and the cervix excised separately.

Specimen.-This consisted "of a uterus and adnexa removed by supravaginal hysterectomy and a cervix with a cuff of vagina. The uterus was $8 \mathrm{~cm}$. in length and $4.5 \mathrm{~cm}$. in width across the fundus. The endometrium was brown in colour and slightly roughened. The right tube and ovary were normal. On the left side, $2.5 \mathrm{~cm}$. from its commencement, the tube became widened and thinwalled, with a maximum diameter of $2.5 \mathrm{~cm}$. Attached to this, at the fimbriated end, there was a solid round buffcoloured tumour measuring $2 \mathrm{~cm}$. in diameter (Fig. 1). The ovary on this side was normal.

Microscopical Examination (Fig. 2).-Sections show that the solid mass at the fimbrial end of the tube is a welldifferentiated adenocarcinoma which has the appearances of a primary tumour of the tube itself. The growth is circumscribed, but it is actively growing and many mitoses are present.

Acknowledgment is made to Dr. G. Stewart Smith for the pathological report and to Mr. C. Dyson, of the Area Pathological Department, for the photographs.

\section{REFERENCES}

Bancroft-Livingston, G. (1946). J. Obstet. Gynaec. Brit. Emp.,

Hu, C. Y., Taymor, M. L., and Hertig, A. T. (1950). Amer. J. Obstet. Gynaec., 59, 58.

Rhu, H. S. (1957). Obstet. and Gynec., 9, 355.

\section{RETINAL HAEMORRHAGES IN SEVERE ANAEMIAS \\ THEIR DIAGNOSTIC SIGNIFICANCE}

BY

J. E. COSNETT, M.B., B.Sc., M.R.C.P.

Edendale Hospital, Pietermaritzburg

AND

I. N. MACLEOD, M.B., Ch.B. King Edward VIII Hospital, Durban

Since the pioneer days of ophthalmoscopy it has been appreciated that retinal haemorrhage may occur in a variety of severe anaemias and blood dyscrasias. Early opinions on the significance of this physical sign were handicapped by lack of correlation with precise haematological diagnosis. These opinions have been perpetuated in some modern writings. A textbook published in 1888 states that " . . . when the corpuscular richness of the blood falls below 50 per cent., whatever the cause of the anaemia, the tendency to retinal haemorrhage is present" (Swanzy, 1888). In a more modern textbook it is written that "retinal haemorrhages, often of a characteristic type, may occur in many blood diseases, varying as a general rule with the degree of anaemia. It seems probable that in such diseases deficient oxygenation may lead to an increase of capillary permeability and consequent increased diapedesis" (Duke-Elder, 1954). Thiel's (1948) atlas contains an illustration of the retinal changes in 